\title{
HEPARIN INDUCED SUBLINGUAL HEMATOMA: A RARE ORAL COMPLICATION
}

\author{
SRIKANTH Gㅜㄹ ABHAY T KAMATH ${ }^{1}$, YOGESH CHHAPARWAL ${ }^{2 *}$, VASANTHA DHARA $^{1}$, ANUPAM SINGH $^{1}$
}

${ }^{1}$ Department of Oral and Maxillofacial Surgery, Manipal College of Dental Sciences, Manipal University, Manipal, Karnataka, India. ${ }^{2}$ Department of Oral Medicine and Radiology, Manipal College of Dental Sciences, Manipal University, Manipal, Karnataka, India. Email: yogesh.omr@gmail.com

Received: 23 May 2017, Revised and Accepted: 29 June 2017

\section{ABSTRACT}

A lingual and sublingual hematoma is a rare complication following heparin therapy which may result in serious life-threatening airway obstruction. A 75-year-old female with ischemic heart disease was heparinized for percutaneous transluminal coronary angioplasty of the left anterior descending artery leading to sublingual hematoma with difficulty in swallowing and breathing. This paper presents a case report and management of sublingual hematoma following heparin therapy.

Keywords: Sublingual hematoma, Heparin, Airway obstruction.

(c) 2017 The Authors. Published by Innovare Academic Sciences Pvt Ltd. This is an open access article under the CC BY license (http://creativecommons. org/licenses/by/4. 0/) DOI: http://dx.doi.org/10.22159/ajpcr.2017.v10i10.20138

\section{INTRODUCTION}

Anticoagulant therapy is indicated for various conditions such as deep venous thrombosis, and vascular thromboembolism. The role of anticoagulants and antiplatelet drugs lies in both treatment and prevention of thromboembolic events in cardiovascular diseases [1]. As a common practice heparin is indicated for the prevention of clotting during cardiac surgery. Among the various complications of heparin therapy, the most common is hemorrhage in the gastrointestinal and intracranial region [2]. However, sublingual hematoma formation as a result of therapeutic heparin therapy is a rare occurrence. We hereby present the case of a heparin induced sublingual hematoma resulting in elevation of the floor of the mouth and tongue leading to airway obstruction.

\section{CASE REPORT}

A 75-year-old female reported to the emergency wing of Kasturba Medical College, Manipal, India, with the chief complaint of chest pain and difficulty in breathing. Her medical history revealed that she is a known case of ischemic heart disease with inferior wall myocardial infarction, hypertension, and double vessel disease. Her drug history revealed that she was on tablet ecosprin $150 \mathrm{mg}$ for the past 5 years. The patient was undertaken for percutaneous transluminal coronary angioplasty of the left anterior descending artery and was given heparin during the procedure. She was kept under observation in intensive care unit where she developed spontaneous sublingual hematoma leading to difficulty in swallowing and breathing. Her vitals were well within the normal limits. Intraoral examination revealed hematoma involving floor of the mouth and lateral border of tongue bilaterally with a superior displacement of the tongue (Fig. 1).

On palpation, submucosal swelling involving the floor of the mouth and ventrolateral aspect of the tongue which was soft in consistency and tender on palpation with restriction in the tongue movements were noted. Laboratory investigation showed that the hemoglobin was low $(6.8 \mathrm{~g} / \mathrm{dl})$ and the bleeding parameters (prothrombin time: 11.1 seconds, activated partial thromboplastin time: 31 seconds, and international normalized ratio: 1.03) were within normal limits. Due to the potential risk of airway compromise, the patient was kept under close observation in the intensive care unit. One dose of corticosteroid injection dexamethasone $(8 \mathrm{mg} / \mathrm{ml})$ was given resulting in a gradual decrease in the size of the swelling over next 2 days with resolution of hematoma.

\section{DISCUSSION}

Anticoagulants are broadly classified into two main types based on their mode of action as oral and injectable. Oral anticoagulants include warfarin which is mainly indicated during long-term treatment whereas heparin is an injectable form is mainly used for immediate short-term procedures. Heparin causes inactivation of thrombin, factor $\mathrm{Xa}$ and other proteases in the clotting cascade by binding and causing conformational change and activation of antithrombin III. Heparin and its derivatives like, low molecular weight heparin is the anticoagulants of choice when the immediate onset of action is required. The onset of the drug is rapid due to its short half-life and duration of action is 2-3 hrs. The common side effect seen during heparin therapy is spontaneous bleeding into the cranium, genitourinary, skin, and gastrointestinal sites. Sublingual involvement is rare. The patients who are on long-term aspirin might potentiate the effects of heparin leading to hematoma formation [3]. In this case, since, the patient was on long-term aspirin and therefore with the administration of heparin, the effect of heparin was potentiated leading to the massive sublingual hematoma. In literature, there is well-established evidence of potential drug-drug interaction involving heparin, clopidogrel, and aspirin which results in increased risk of bleeding [4]. The tongue is one of

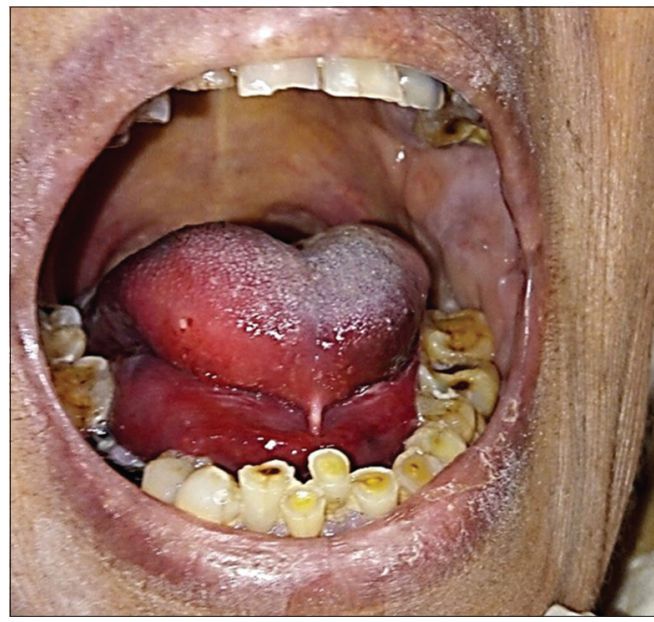

Fig. 1: Intraoral view showing formation of sublingual hematoma 
the most common sites of hematoma formation due to the extensive vascular supply by the lingual artery and its branches. A sublingual hematoma is a common complication seen following warfarin and streptokinase leading to the upper airway obstruction [5]. The case reported here is unique as hematoma formation secondary to administration of heparin is rare. The clinician should be well versed this potential complication of heparin and be competent enough to manage the airway complication. The sublingual hematomas caused by anticoagulants can be managed by both surgical and nonsurgical methods. However, surgical intervention in the form of incision and drainage has a lot of complications and unsafe for the patients. The nonsurgical plan of treatment is more beneficial for the patient. Closely monitoring of the patient is very important for immediate intervention in the case of the upper airway obstruction [6].

\section{CONCLUSION}

The present case demonstrates potentially life-threatening spontaneous sublingual hematoma leading to the upper airway obstruction with the dual action of heparin and aspirin. Therefore, health practitioners should be aware of this complication and be able to diagnose and manage this medical emergency.

\section{REFERENCES}

1. Kumar M, Dahiya V, Mishra S, Sharma D, Mishra N, Lahkar M. Cardiovascular disease prevalence and drug utilization patterns at a tertiary care hospital in Northeastern India. Int J Pharm Pharm Sci 2016;8(6):116-9.

2. Williams PJ, Jani P, McGlashan J. Lingual haematoma following treatment with streptokinase and heparin; Anaesthetic management. Anaesthesia 1994;49(5):417-8.

3. Yett HS, Skillman JJ, Salzman EW. The hazards of aspirin plus heparin. N Engl J Med 1978;298(19):1092.

4. Venkateswaramurthy N, Krishnaveni K, Freeda RM, Kumar RS Assessment of potential drug-drug interaction in stroke patients. Int $\mathrm{J}$ Pharm Pharm Sci 2016;8(12):221-4.

5. Berthelsen RE, Tadbiri S, Rosenstock CV. Spontaneous sublingual haematoma in a patient treated with warfarin. Acta Anaesthesiol Scand 2013;57(4):530-1.

6. Frohna WJ, Lowery RC Jr, Pita F. Lingual and sublingual hematoma causing upper airway obstruction. J Emerg Med 2012;43(6):1075-6. 